\title{
Electric Vehicle Preparedness: Task 1, Assessment of Fleet Inventory for Marine Corps Base Camp Lejeune
}

Stephen Schey

Jim Francfort

January 2015

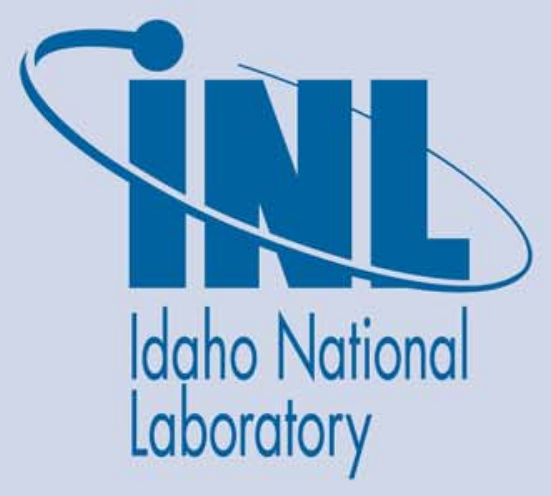

The INL is a U.S. Department of Energy National Laboratory operated by Battelle Energy Alliance 


\title{
Electric Vehicle Preparedness: Task 1, Assessment of Fleet Inventory for Marine Corps Base Camp Lejeune
}

\author{
Stephen Schey \\ Jim Francfort \\ Stephen Schey, Project Manager, Infrastructure Planning and Analysis, Intertek Testing Services, \\ Jim Francfort, Vehicle Systems Principal Investigator, Idaho National Laboratory operated by \\ Battelle Energy Alliance, Idaho Falls, ID \\ January 2015
}

Idaho National Laboratory

Idaho Falls, Idaho 83415

http://avt.inl.gov

Prepared for the

U.S. Department of Energy

Office of Nuclear Energy

Under DOE Idaho Operations Office

Contract DE-AC07-05ID14517 


\section{DISCLAIMER}

This information was prepared as an account of work sponsored by an agency of the U.S. Government. Neither the U.S. Government nor any agency thereof, nor any of their employees, makes any warranty, expressed or implied, or assumes any legal liability or responsibility for the accuracy, completeness, or usefulness, of any information, apparatus, product, or process disclosed, or represents that its use would not infringe privately owned rights. References herein to any specific commercial product, process, or service by trade name, trade mark, manufacturer, or otherwise, does not necessarily constitute or imply its endorsement, recommendation, or favoring by the U.S. Government or any agency thereof. The views and opinions of authors expressed herein do not necessarily state or reflect those of the U.S. Government or any agency thereof. 


\section{ABSTRACT}

Battelle Energy Alliance, LLC, managing and operating contractor for the U.S. Department of Energy's Idaho National Laboratory, is the lead laboratory for the U.S. Department of Energy's advanced vehicle testing. Battelle Energy Alliance, LLC contracted with Intertek Testing Services, North America (Intertek) to conduct several U.S. Department of Defense-based studies to identify potential U.S. Department of Defense transportation systems that are strong candidates for introduction or expansion of plug-in electric vehicles (PEVs).

Task lincluded a survey of the inventory of non-tactical fleet vehicles at the Marine Corps Base Camp Lejeune (MCBCL) to characterize the fleet. This information and characterization will be used to select vehicles for monitoring that takes place during Task 2 . This monitoring involves data logging of vehicle operation in order to identify the vehicle's mission and travel requirements. Individual observations of these selected vehicles provide the basis for recommendations related to PEV adoption. It also identifies whether a battery electric vehicle or plug-in hybrid electric vehicle (collectively referred to as PEVs) can fulfill the mission requirements and provides observations related to placement of PEV charging infrastructure.

This report provides the results of the assessments and observations of the current non-tactical fleet, fulfilling the Task 1 requirements.

Intertek acknowledges the support of Idaho National Laboratory, the Marine Corps headquarters, and MCBCL fleet management and personnel for participation in this study.

Intertek is pleased to provide this report and is encouraged by the enthusiasm and support from MCBCL personnel. 


\section{EXECUTIVE SUMMARY}

Federal agencies are mandated ${ }^{a}$ to purchase alternative fuel vehicles, increase consumption of alternative fuels, and reduce petroleum consumption. Available plug-in electric vehicles (PEVs) provide an attractive option in the selection of alternative fuel vehicles. PEVs, which consist of both battery electric vehicles and plug-in hybrid electric vehicles, have significant advantages over internal combustion vehicles in terms of energy efficiency, reduced petroleum consumption, and reduced production of greenhouse gas emissions, and they provide performance benefits with quieter, smoother operation. This study intended to evaluate the extent to which the Marine Corps Base Camp Lejeune (MCBCL) could convert part or all of their fleet of vehicles from petroleum-fueled vehicles to PEVs.

The study begins with an assessment of the existing non-tactical fleet of vehicles at MCBCL to characterize its current components in order to conduct an in-depth assessment of representative vehicles. This leads to specific results for these selected vehicles and wider extrapolation to the full fleet of vehicles.

MCBCL borders on the Atlantic Ocean near Jacksonville, North Carolina. The base and surrounding community is home to an active duty, dependent, retiree, and civilian employee population of approximately 170,000 people. Camp Lejeune contains 156,000 acres and 11 miles of beaches. ${ }^{b}$ The size of the main base, as well as its proximity to nearby related bases of Camp Johnson, Marine Corps Air Station at New River, Camp Geiger, Stone Bay, Courthouse Bay, and the Greater Sandy Run Training Area, make it an ideal study site for the adoption of PEVs.

PEVs that are currently commercially available cannot replace certain vehicles and missions, such as those requiring heavy-duty trucks and specialty usage vehicles. However, the MCBCL non-tactical fleet contains 862 vehicles for which counterpart PEVs are currently available or which are expected to be available in the near future. From these 862 vehicles, 60 vehicles will be selected for further monitoring and evaluation.

${ }^{a}$ Energy Policy act of 1992, Energy Policy Act of 2005, Executive Order 13423, and Energy Independence and Security Act of 2007.

${ }^{\mathrm{b}}$ www.lejeune.marines.mil/About.aspx accessed January 22, 2015. 


\section{CONTENTS}

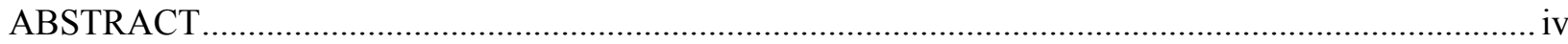

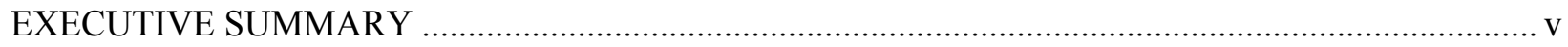

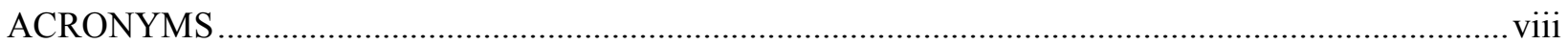

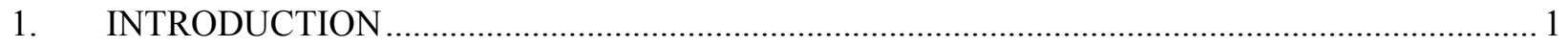

2. MARINE CORPS BASE CAMP LEJEUNE FLEET INVENTORY DATA SUMMARY ............. 1

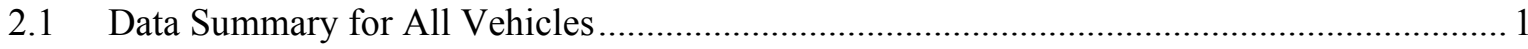

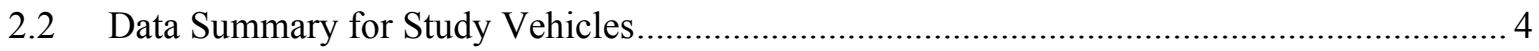

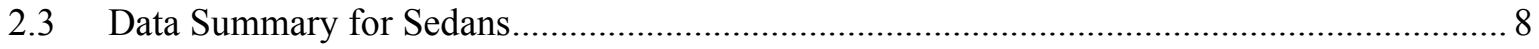

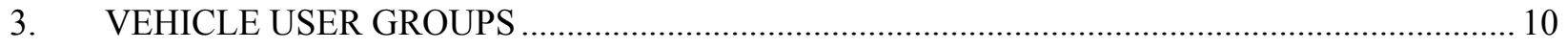

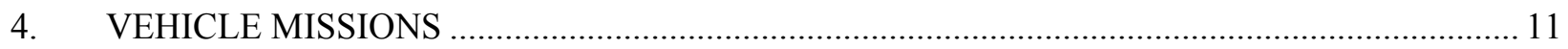

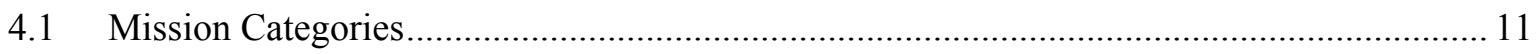

4.2 Vehicle Mission of Marine Corps Base Camp Lejeune Inventory .................................... 12

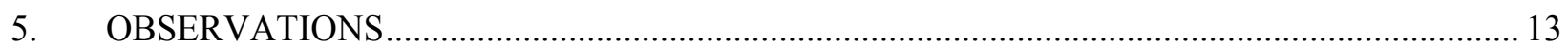

\section{FIGURES}

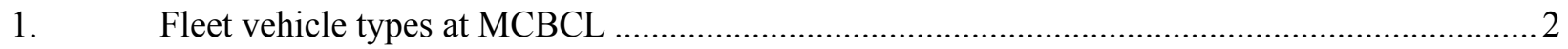

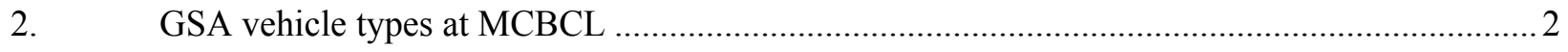

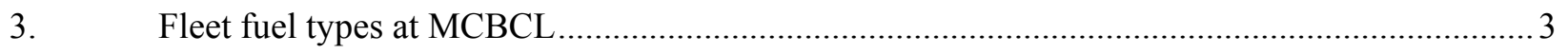

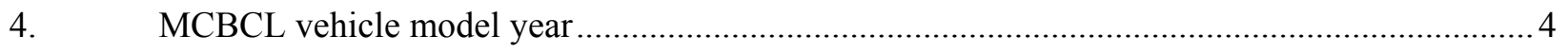

5. MCBCL studied fleet inventory composition.................................................................... 4

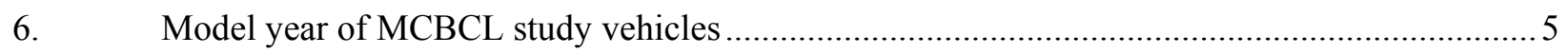

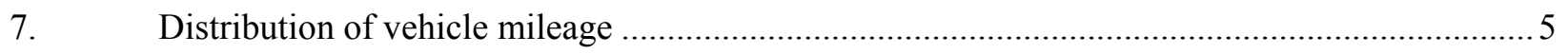

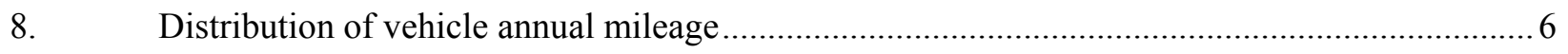

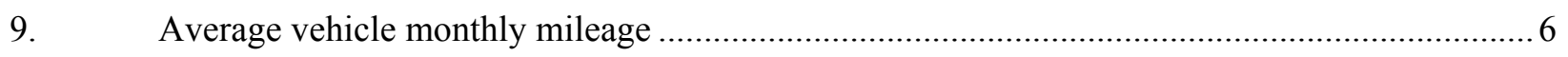

10. Projected replacement year for current fleet inventory …................................................... 7 


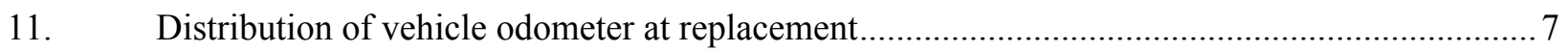

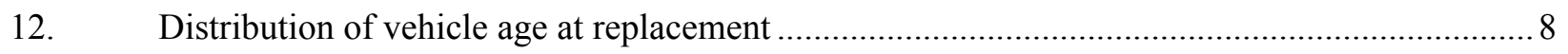

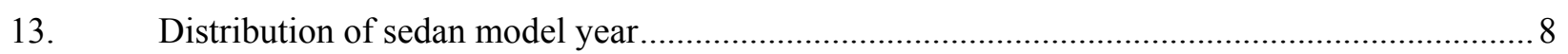

14. Monthly mileage comparison sedans to all vehicles .......................................................... 9

15. Cumulative distribution of sedan odometer readings ......................................................... 9

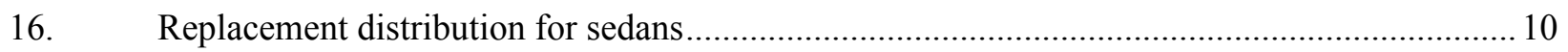

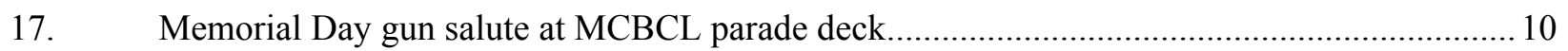

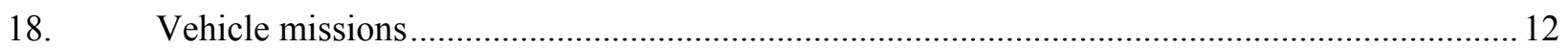

\section{TABLES}

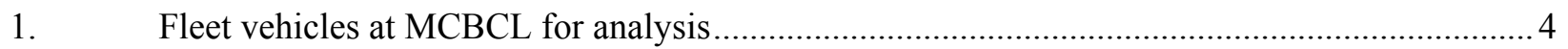

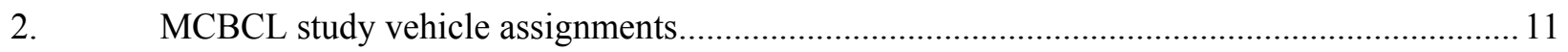

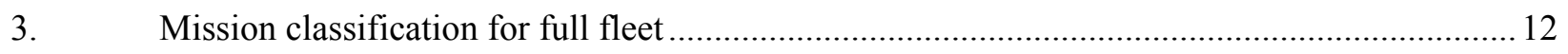

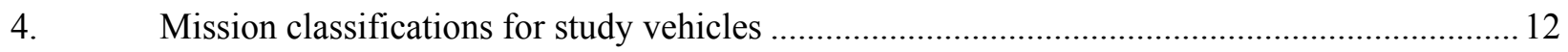

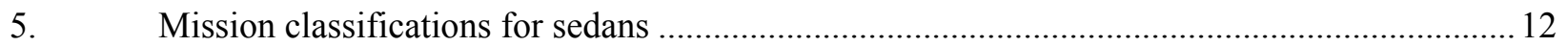




\section{ACRONYMS}

BEV battery electric vehicle

EPA U.S. Environmental Protection Agency

GSA General Services Administration

Intertek Intertek Testing Services, North America

MCBCL Marine Corps Base Camp Lejeune

MCIE Marine Corps Installations East

MEF Marine Expeditionary Force

MOU memorandum of understanding

PEV plug-in electric vehicle (includes BEVs and PHEVs, but not hybrid electric vehicles)

PHEV plug-in hybrid electric vehicle

SUV sports utility vehicle 


\section{Electric Vehicle Preparedness: Task 1, Assessment of Fleet Inventory for Marine Corps Base Camp Lejeune}

\section{INTRODUCTION}

The U.S. Department of Energy and the U.S. Department of Defense signed a memorandum of understanding (MOU) on July 22, 2010, for strengthening the coordination of efforts to enhance national energy security and to demonstrate federal government leadership in transitioning the United States to a low-carbon economy. The MOU included efforts in the areas of energy efficiency, fossil fuels, alternative fuels, efficient transportation technologies and fueling infrastructure, grid security, smart grid, and energy storage.

In support of the MOU, Idaho National Laboratory, with funding provided by the U.S. Department of Energy's Vehicle Technologies Office and Federal Energy Management Program, directed Intertek Testing Services, North America (Intertek) to conduct several U.S. Department of Defense-based studies. These studies were conducted to identify potential transportation systems that are strong candidates for introduction or expansion of plug-in electric vehicles (PEVs). Intertek previously has conducted similar fleet, city, state, and countrywide studies using their EV Micro-Climate ${ }^{\circledR}$ assessment process, which consists of the following four main tasks:

- Task 1: Conduct a non-tactical vehicle fleet assessment

- Task 2: Monitor select vehicles for mission and fleet characterizations

- Task 3: Perform detailed assessment of selected vehicles and charging infrastructure needs

- Task 4: Prepare adoption approach for PEVs and charging infrastructure.

Assessment of the potential for replacing Marine Corps Base Camp Lejeune (MCBCL) fleet vehicles with PEVs starts with characterization of fleet vehicle missions and vehicle characteristics. This assessment is conducted through a detailed review of the fleet inventory and discussions with site personnel. This Task 1 report provides a summary and assessment of the fleet data and survey results.

PEVs generally are classified into two vehicle types: (1) battery electric vehicles (BEVs) and (2) plug-in hybrid electric vehicles (PHEVs). BEVs are vehicles where all of the motive power is provided by an onboard battery. For PHEVs, an onboard battery provides some of the motive power, but this battery power is supplemented by another power source (e.g., a gasoline engine). Collectively, BEVs and PHEVs are known as PEVs.

Section 2 provides characterization of the current fleet at MCBCL. Section 2.1 presents the data summary for all fleet vehicles. Section 2.2 provides information for all sedans, light trucks, and medium trucks, which will be the detailed focus of this study. Section 2.3 further defines sedans only because they are the only vehicles currently available from the General services Administration (GSA). Section 3 identifies the user groups for these vehicles and Section 4 provides the classification of vehicle missions and relates these missions to MCBCL vehicles. Finally, Section 5 provides observations related to this current task.

\section{MARINE CORPS BASE CAMP LEJEUNE FLEET INVENTORY DATA SUMMARY}

\subsection{Data Summary for All Vehicles}

The non-tactical fleet of vehicles in the inventory managed by MCBCL consists of 862 vehicles, excluding non-powered trailers, material handling equipment, low-speed vehicles, and buses. Currently, 62 specialty pieces of equipment (e.g., fire protection vehicles, aerial boom/bucket trucks, ambulance, etc.) and 78 heavy-duty trucks (e.g., tractors, dump trucks, etc.) are identified in the full fleet makeup. Although there are PEV demonstrators of many of these vehicles, they are not current standard PEV 
models or may have special charging needs. Several PEV types are available for potential replacement for the balance of the vehicles.

There are 648 GSA leased and 214 Marine Corps owned vehicles in this fleet. The GSA and Marine Corps categories provide information on the vehicles, but more common vehicle types are provided in the U.S. Environmental Protection Agency (EPA) classifications. Using EPA definitions and general classifications, the current fleet makeup is shown in Figure 1.

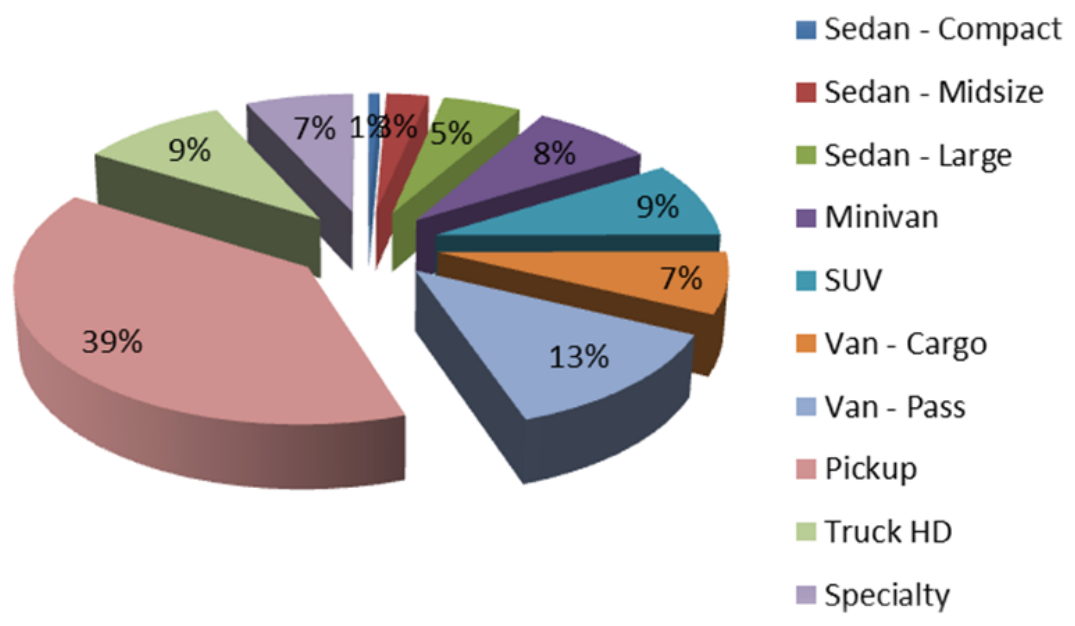

Figure 1. Fleet vehicle types at MCBCL.

Converting the Marine Corps vehicle classifications into the GSA classifications, Figure 2 shows the GSA classifications of all vehicles.

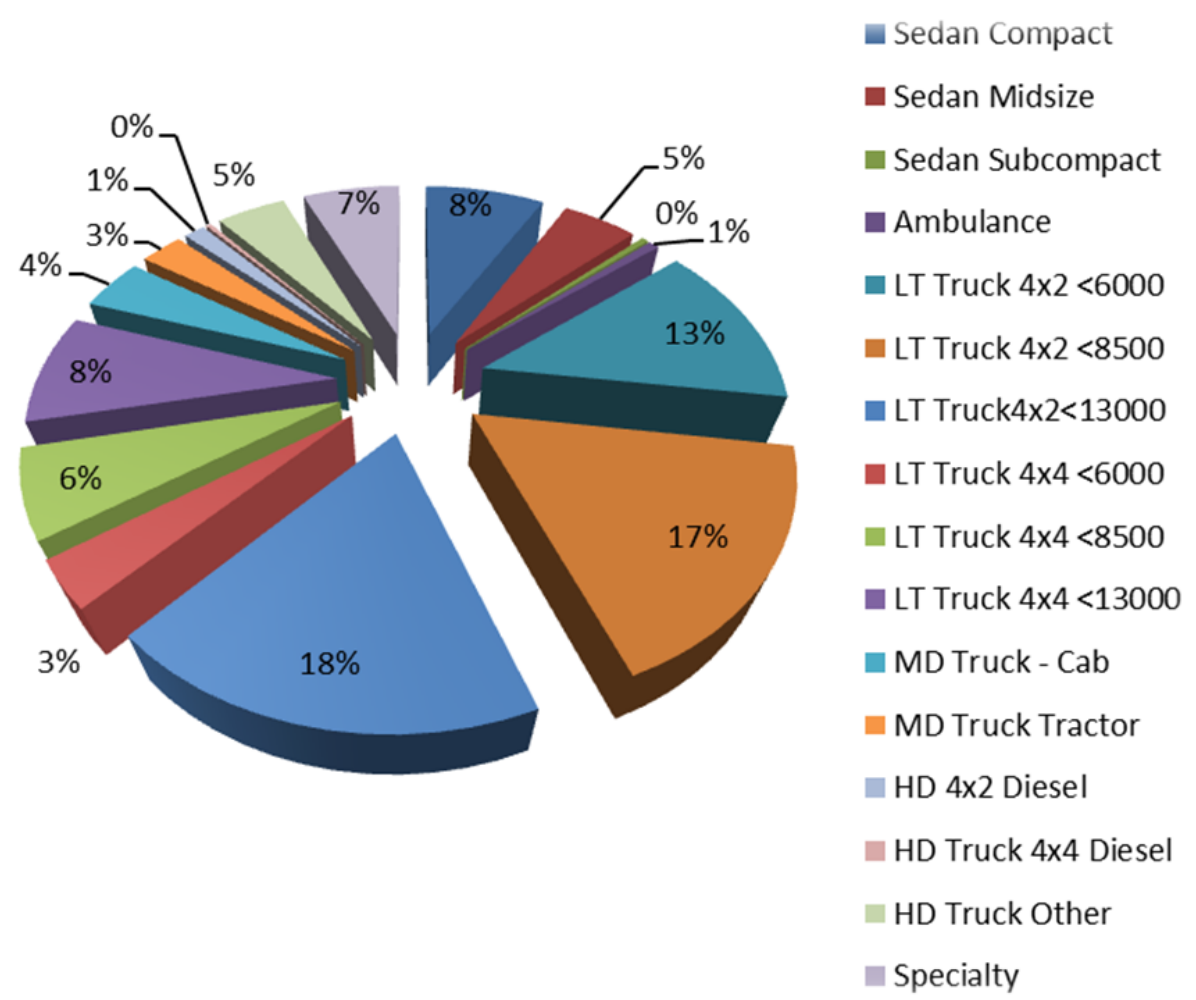

Figure 2. GSA vehicle types at MCBCL. 
There are some differences between the GSA list and EPA list for sedans. Specifically, GSA lists the classification G10 as compact, but the vehicles are either compact, midsize, or sport utility vehicle (SUV) per EPA. GSA classification G11 is a midsize sedan, but all sedans are Chevrolet Impalas that the EPA classifies as large. GSA classification G13 is subcompact, but EPA shows these vehicles as compact.

The Marine Corps-owned vehicles make up approximately $25 \%$ of the vehicles and include all of the specialty vehicles (except six ambulances) and all of the heavy-duty trucks.

Figure 3 shows the fuel type distribution for these vehicles. Vehicles available as E85 are strictly controlled by MCBCL to use E85 exclusively. The vehicles marked as gasoline are gasoline only. As can be seen in the figure, E85-fueled vehicles comprise the majority of the vehicles.

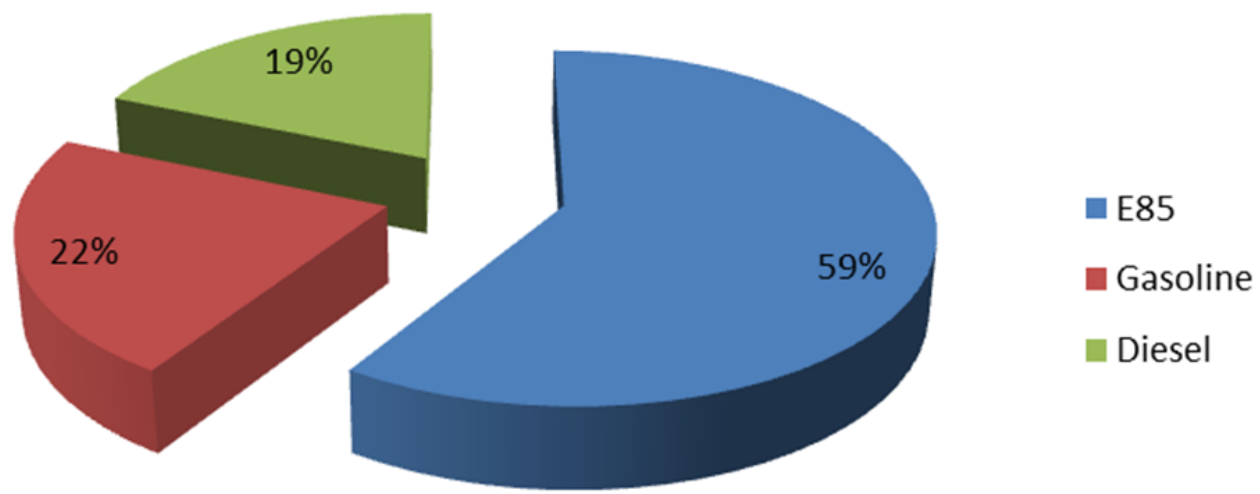

Figure 3. Fleet fuel types at MCBCL.

The 191 vehicles fueled by gasoline are sedans, pickup trucks, SUVs, and vans and are the most likely candidates for replacement by PEVs because, to date, auto manufacturers have focused on providing PEVs of this size. The E85-fueled vehicles already use alternative fuels but may also be considered for PEV replacement because PEVs can provide benefits in greater reductions in emissions and potential fuel cost savings. This will be explored in detail in Tasks 3 and 4 .

Diesel-fueled vehicles also make up a sizeable fraction of the fleet; diesel is the predominant fuel used in larger vehicles. Medium-duty trucks may be candidates for replacement by PEVs because manufacturers plan to provide more vehicles of this size in the coming years. Many of the specialty vehicles to be evaluated later are diesel-fueled.

The vehicle model year for all vehicles is shown in Figure 4.

The 29 vehicles of model year 2000 or older are all Marine owned and typically heavy-duty trucks or specialty vehicles. Four cargo vans and two pickups are also included and are likely to be replaced in the next few years. 


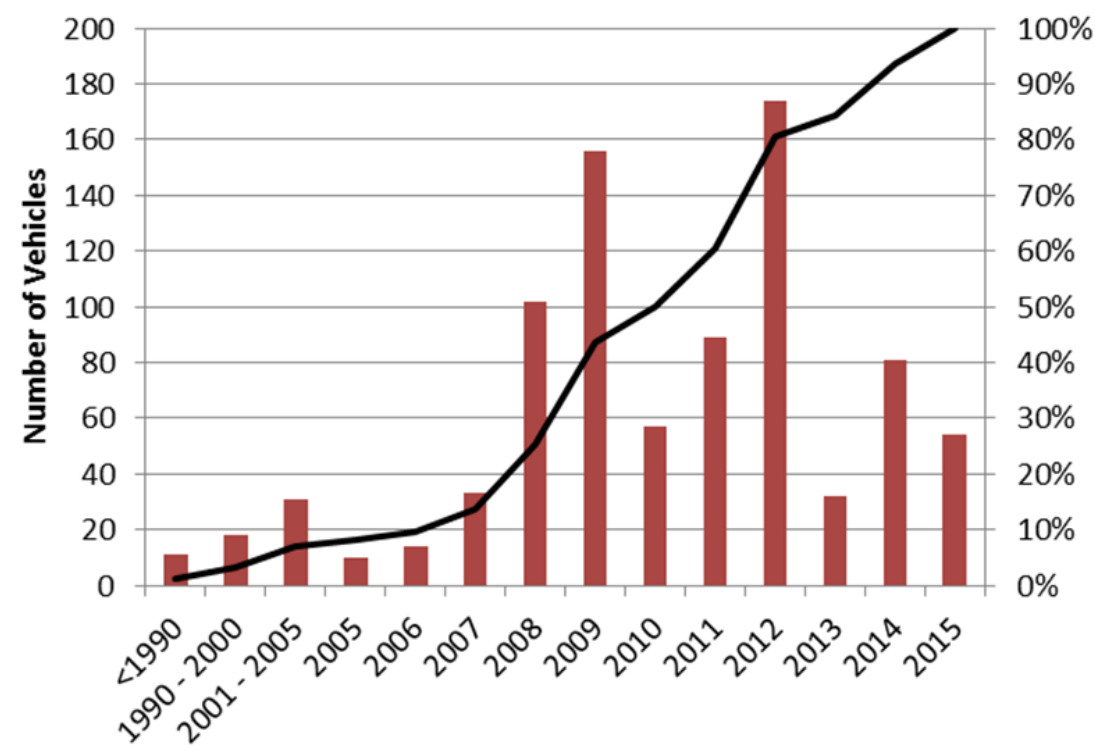

Figure 4. MCBCL vehicle model year.

\subsection{Data Summary for Study Vehicles}

The PEVs currently available for replacing the heavy-duty trucks and specialty vehicles are primarily conversion of existing vehicle body types. While the heavy-duty trucks will be excluded from this study, some of the current specialty vehicles will be monitored to obtain further information. For the 784 vehicles included in this study, this section provides a summary of data for these vehicles per the GSA definition. These vehicles are most likely to be replaced by PEVs in the near term. Table 1 identifies the vehicles by EPA classification from which the monitored vehicles will be selected.

Table 1. Fleet vehicles at MCBCL for analysis.

\begin{tabular}{|c|c|c|c|c|c|c|c|c|c|c|}
\hline & $\begin{array}{c}\text { Sedan - } \\
\text { Compact }\end{array}$ & $\begin{array}{l}\text { Sedan - } \\
\text { Midsize }\end{array}$ & $\begin{array}{l}\text { Sedan - } \\
\text { Large }\end{array}$ & Minivan & SUV & $\begin{array}{l}\text { Van } \\
\text { Cargo }\end{array}$ & $\begin{array}{l}\text { Van } \\
\text { Pass }\end{array}$ & Pickup & Specialty & Total \\
\hline Quantity & 6 & 23 & 43 & 67 & 76 & 62 & 109 & 336 & 62 & 784 \\
\hline Percent & 1 & 3 & 5 & 9 & 10 & 8 & 14 & 43 & 8 & 100 \\
\hline
\end{tabular}

Figure 5 shows the composition of the fleet vehicles that are the focus of this study. Fully $43 \%$ of the vehicles are pickup trucks, while $9 \%$ are sedans.

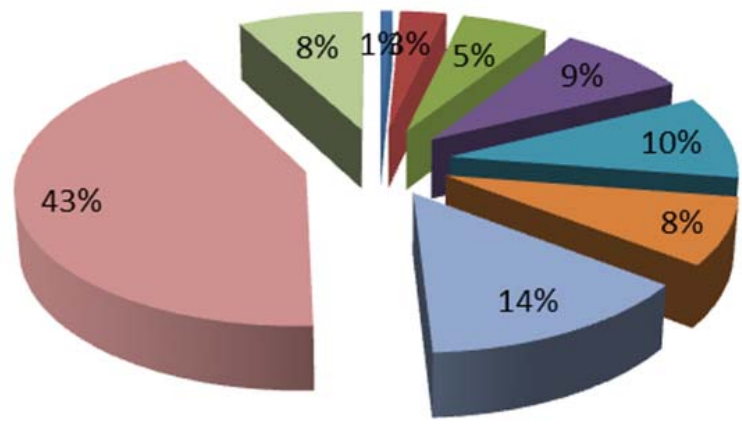

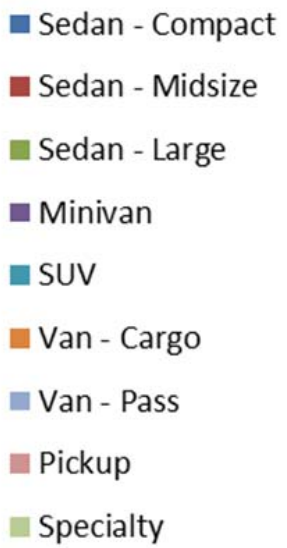

Figure 5. MCBCL studied fleet inventory composition. 
The model years of the vehicles under study are shown in Figure 6. The age of the current fleet is rather young, with $60 \%$ of the vehicles having model year 2010 or newer. Nevertheless, $5 \%$ are more than 10 years old, with the oldest vehicles in operation being fire trucks of model year 1985 and with an annual usage of approximately 1,600 miles.

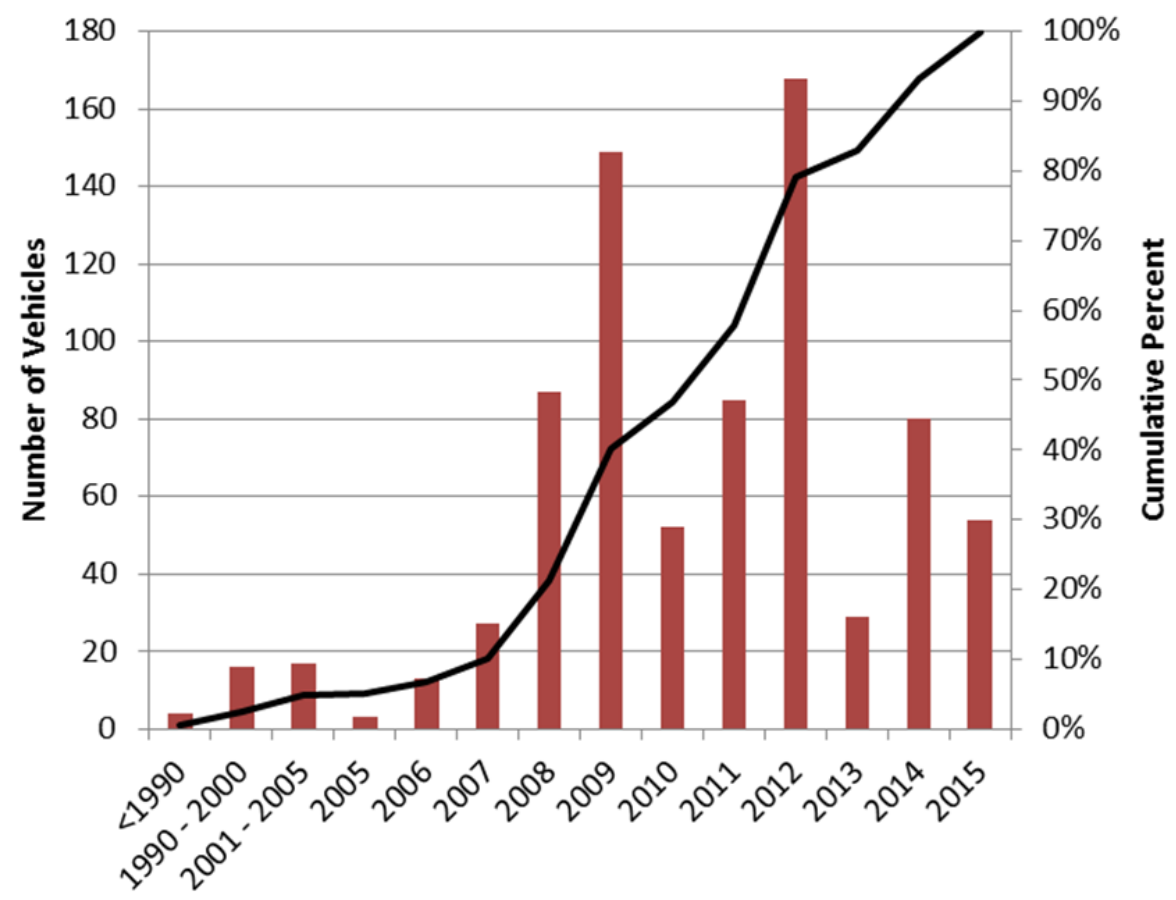

Figure 6. Model year of MCBCL study vehicles.

The distribution of the most recent odometer readings of the 784 vehicles is shown in Figure 7 . The odometer readings of 319 vehicles (41\%) show less than 20,000 miles. On the other hand, seven vehicles have recent odometer readings exceeding 80,000 miles, with the highest at 96,259 miles. Three of these seven vehicles are enforcement vehicles. See Section 3 for further discussion of vehicle mission related to enforcement activities.

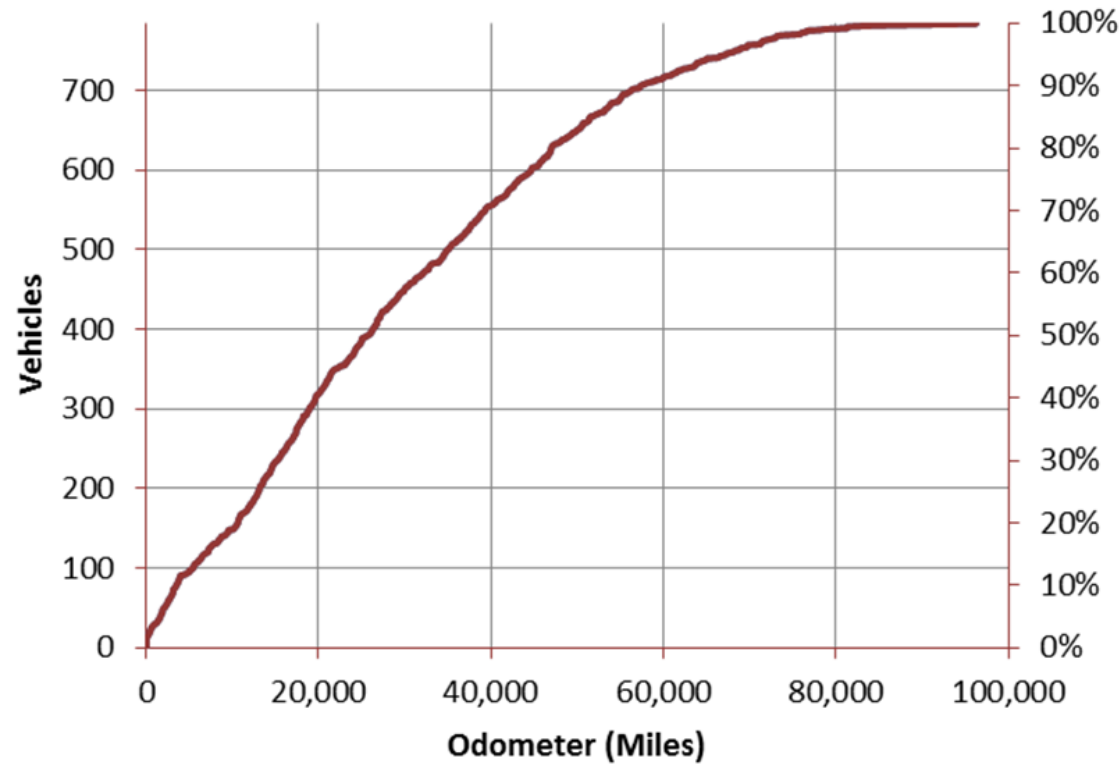

흘

Figure 7. Distribution of vehicle mileage. 
The annual mileage of the study fleet is shown in Figure 8. Some $75 \%$ of the vehicles are driven less than 10,000 miles each year, which is an average of less than 200 miles per week or 40 miles per workday. Sixteen of the top 20 vehicles with the heaviest usage are used in enforcement activities.

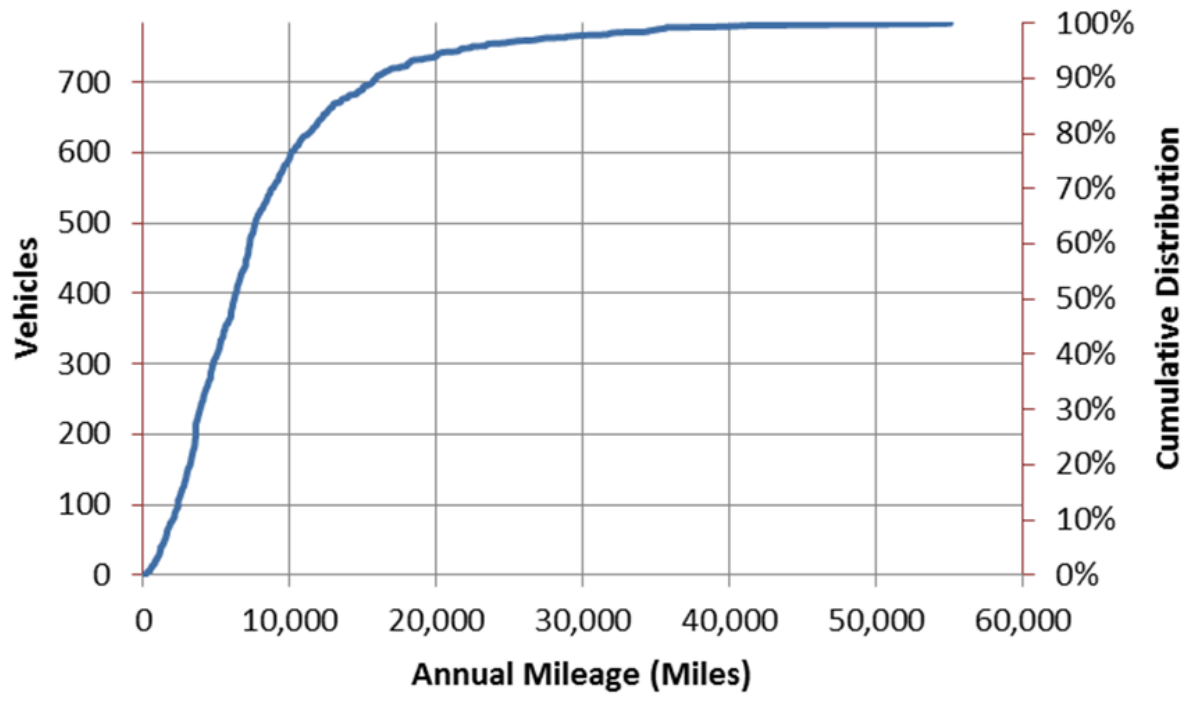

Figure 8. Distribution of vehicle annual mileage.

Of particular interest is the monthly mileage of the studied fleet (Figure 9). If one assumes a battery range of 70 miles for a BEV and 21 working days per month, then a vehicle that consistently travels the same distance each day would have to travel greater than approximately 1,500 miles per month to exceed the batter capacity. As shown in Figure 9, approximately 91\% of MCBCL cars, light trucks, medium trucks, and specialty vehicles have average travel that is less than 1,400 miles per month. Therefore, barring charging constraints associated with the timing of daily mission activities, payload requirements, and range issues associated with off-base trips, a significant number of vehicles should be eligible for replacement by BEVs.

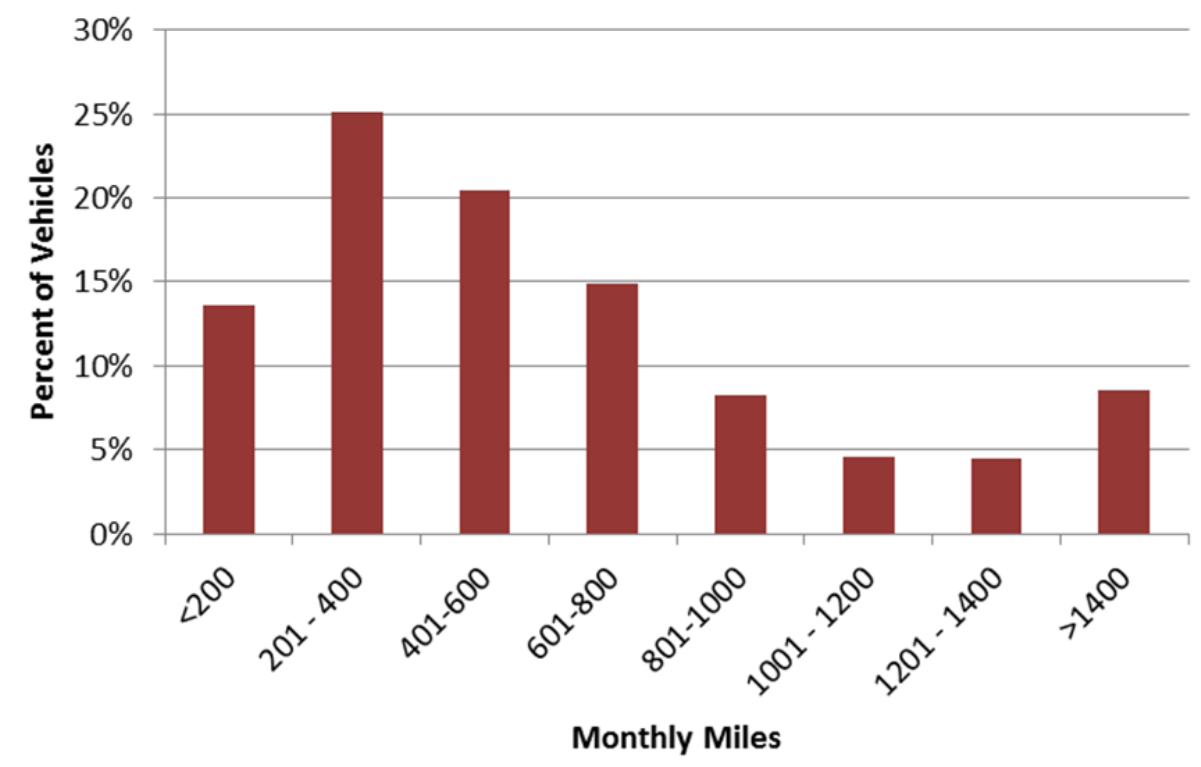

Figure 9. Average vehicle monthly mileage. 
GSA publishes the minimum requirements for vehicle replacement. MCBCL typically has exceeded these requirements prior to replacing the vehicles. Extrapolating the annual miles provided, along with recent odometer readings, with GSA requirements (as a minimum), the replacement year of these fleet vehicles was determined. Note that an upper limit of 2035 (20 years away) was arbitrarily used as the replacement of any remaining existing vehicles. Figure 10 shows the projected number of vehicles to be replaced each year. This information will be used in Task 4 to present a replacement approach.

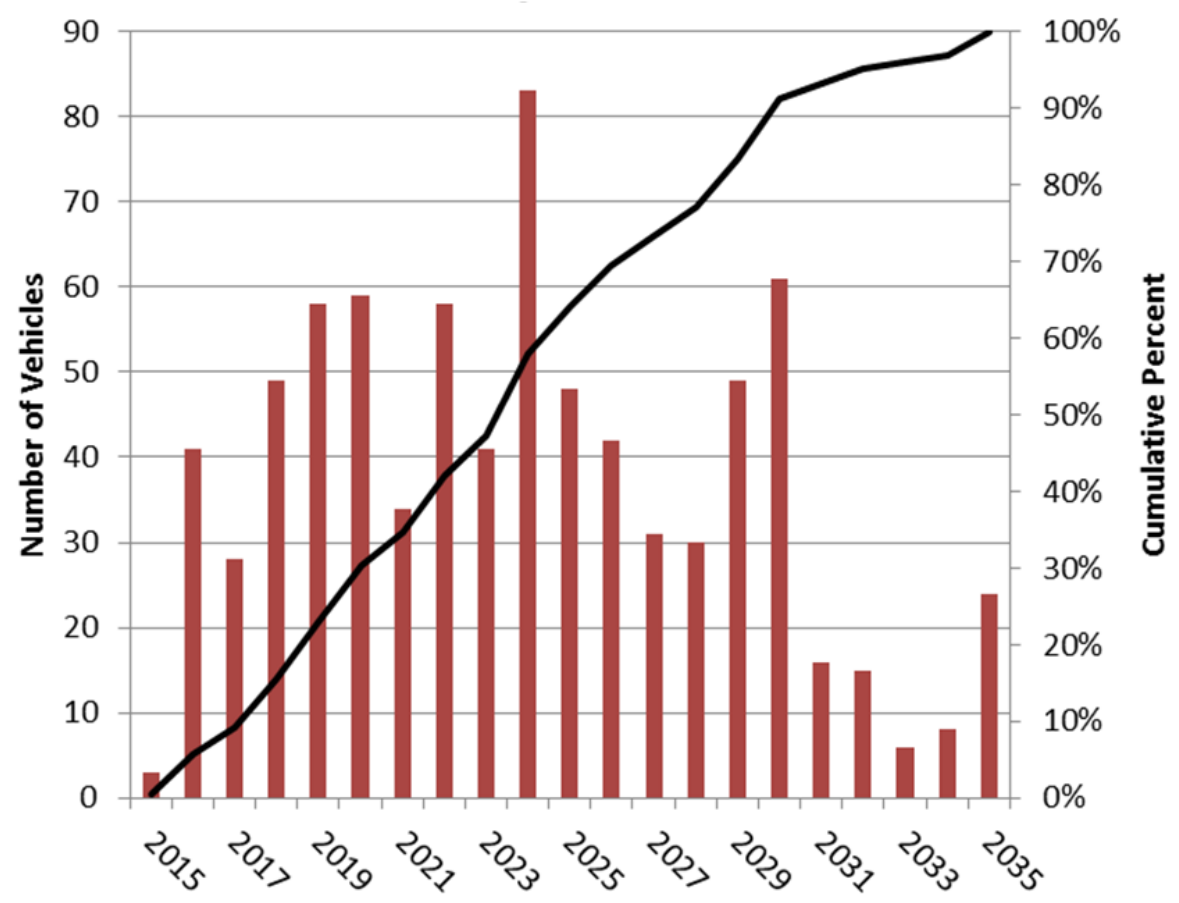

Figure 10. Projected replacement year for current fleet inventory.

Figure 11 shows the cumulative distribution of vehicle odometer readings at replacement. The mean and median projected odometer readings of the replaced vehicles are 77,581 and 82,319 miles, respectively.

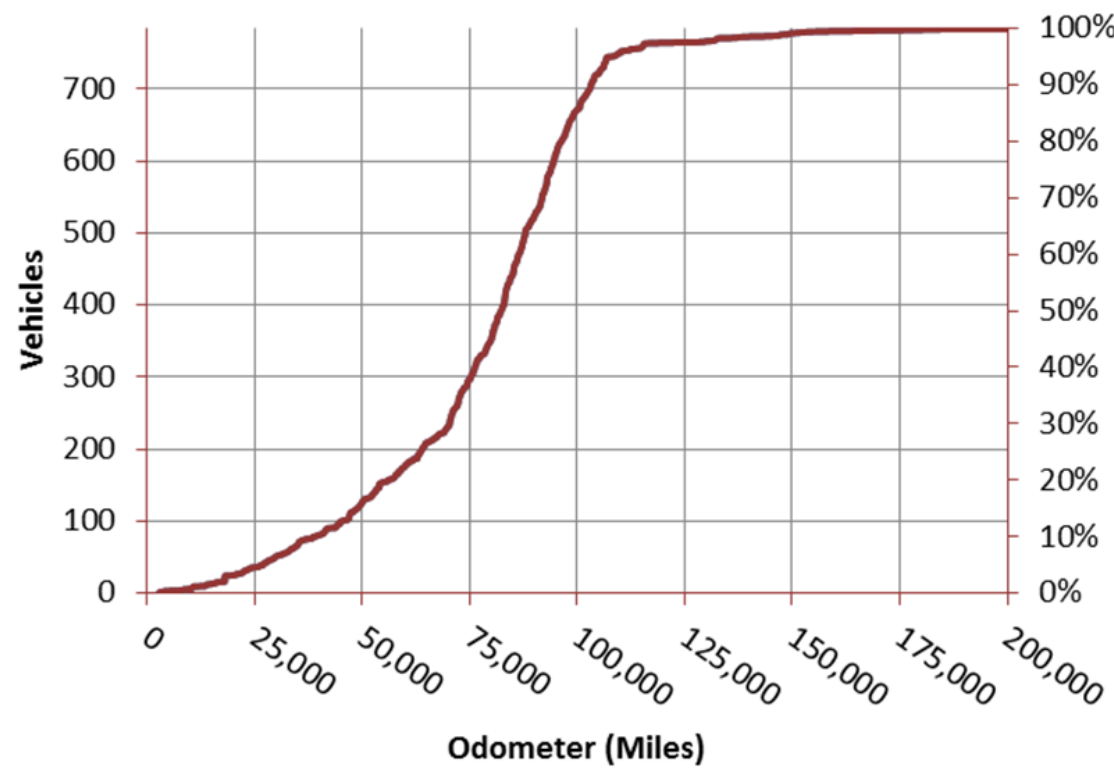

Figure 11. Distribution of vehicle odometer at replacement. 
Twenty-one vehicles (2.6\%) are projected to have odometer readings exceeding 120,000 miles at replacement. Nineteen of these vehicles are specialty vehicles that typically have long service lives. Two vehicles are pickup trucks with current odometer readings exceeding 80,000 miles and with high annual usage that are projected to be replaced in 2016.

Figure 12 shows the cumulative distribution of vehicle age at replacement. The mean and median ages of the replaced vehicle are 14 years old.

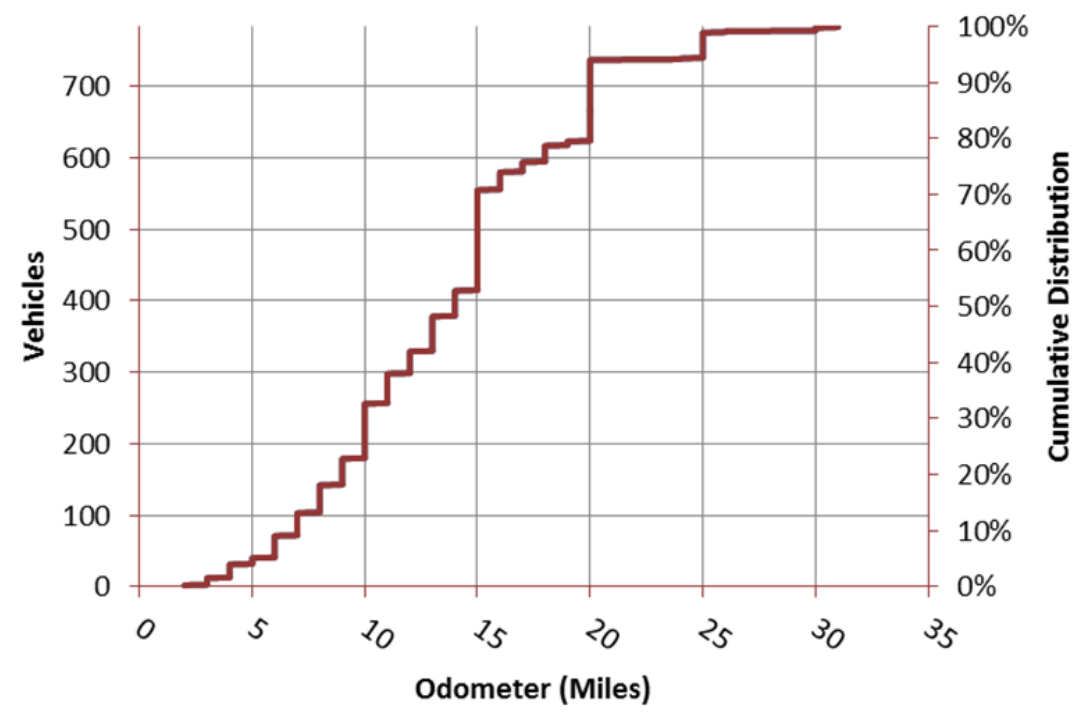

Figure 12. Distribution of vehicle age at replacement.

The age of the vehicle at replacement usually exceeds the GSA minimum requirements of 3 to 10 years (depending on vehicle type). The odometer reading at replacement exceeds the minimum for sedans $(36,000)$ and is near the minimum for light trucks $(65,000)$. This again reflects the relatively low annual travel usage of the vehicles.

\subsection{Data Summary for Sedans}

This section provides a summary of data for sedans. Sedans are reviewed separately because, at the time of this writing, only sedan-type vehicles populate the GSA list for PEVs. There are 72 sedans in the fleet of vehicles. Figure 13shows the distribution of sedan model years. Fully 83\% are model year 2012 or newer.

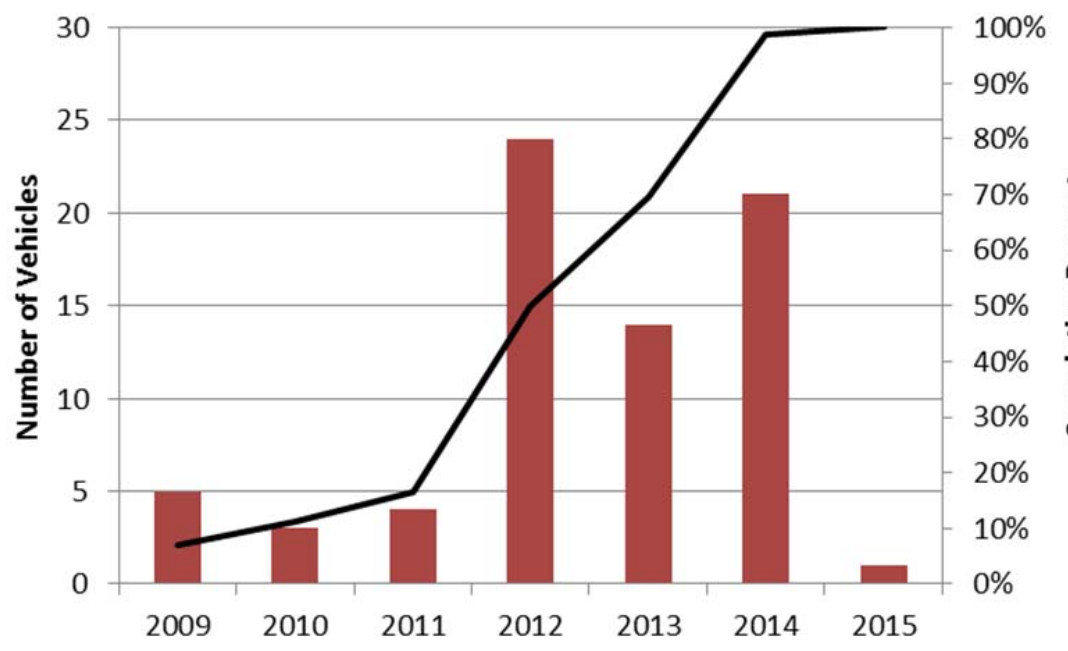

Figure 13. Distribution of sedan model year. 
Similar to Section 2.2, sedans have a monthly mileage distribution that indicates that the range generally should not be a concern for at least half of the vehicles. Figure 14 shows that sedans have higher monthly usage than the average of all vehicles studied.

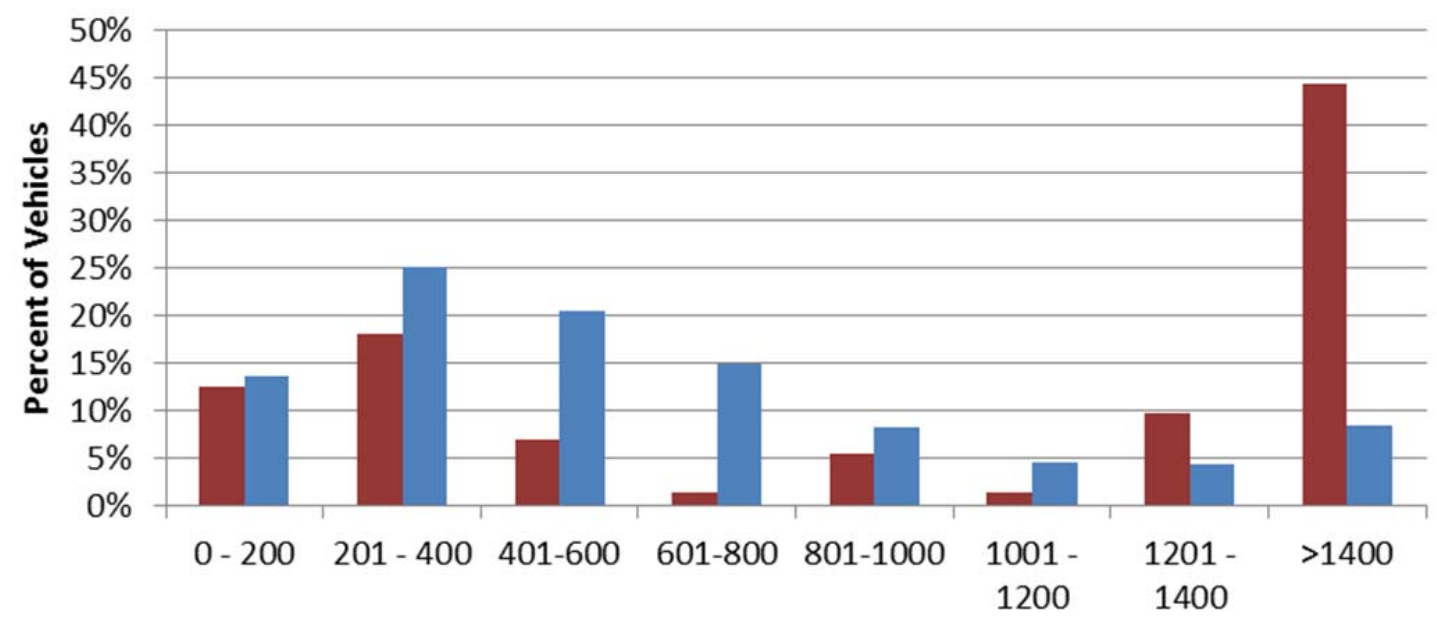

Monthly Miles

Sedans $\quad$ All Vehicles

Figure 14 . Monthly mileage comparison sedans to all vehicles.

Figure 15 shows the cumulative distribution of the current sedan odometer readings. Six vehicles have current odometer readings exceeding 75,000 miles and all but one are used in enforcement activities.

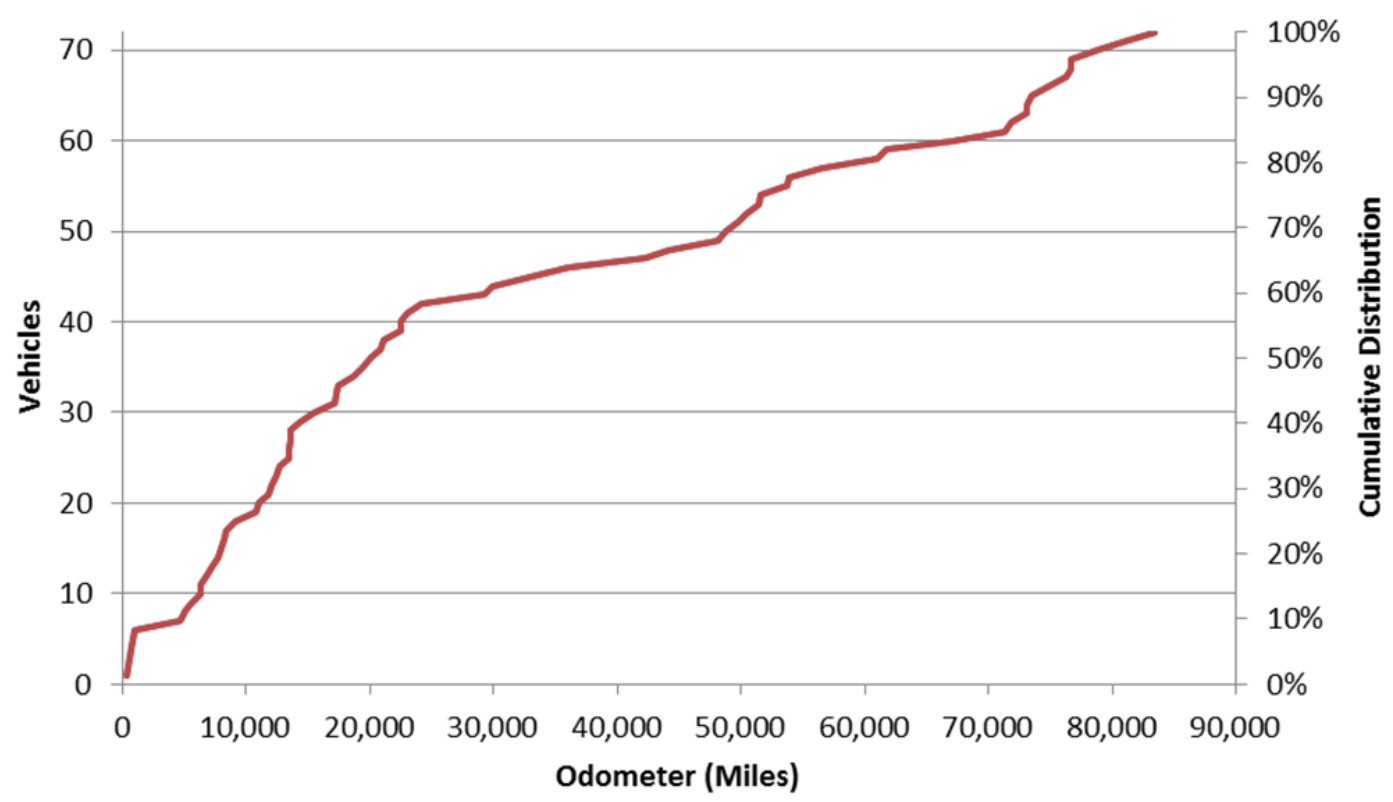

Figure 15. Cumulative distribution of sedan odometer readings.

Figure 16 shows the projected year of replacement for the sedans. The peaks in the next few years are due to the high mileage of many of the vehicles.

As before, the projected age of replacement will be used in future reports, providing a replacement approach for incorporating PEVS. 


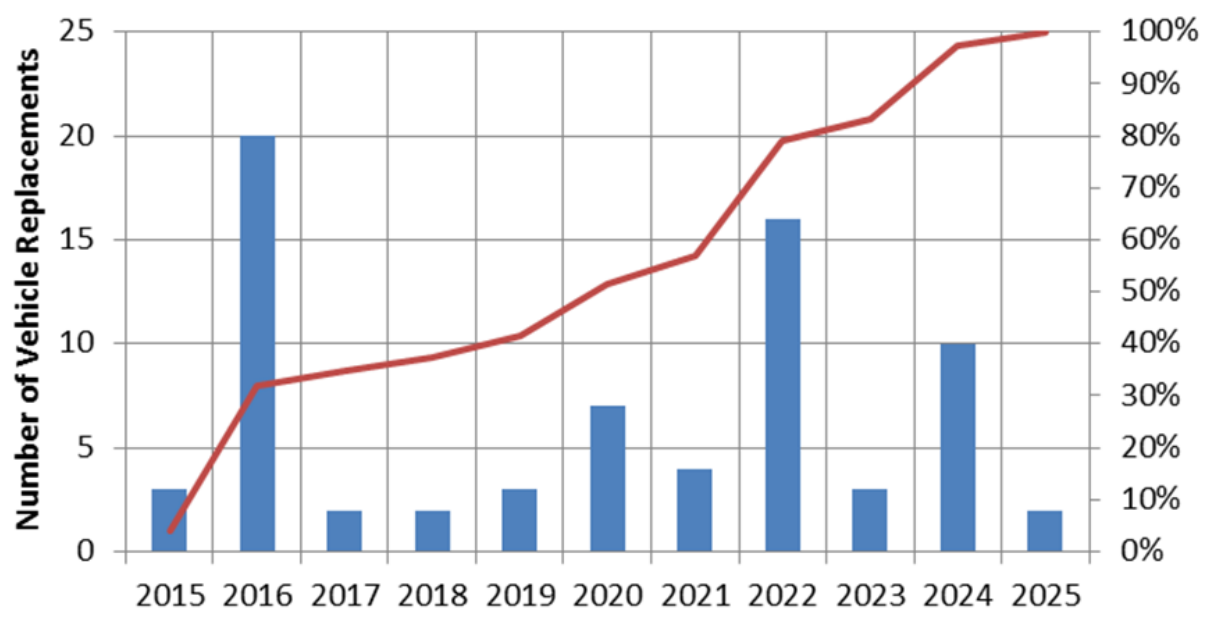

品

Figure 16. Replacement distribution for sedans.

\section{VEHICLE USER GROUPS}

Since September 1941, Camp Lejeune has been the home of Expeditionary Forces in Readiness and, throughout the years, it has become the home base for the II Marine Expeditionary Force (MEF), 2nd Marine Division, 2nd Marine Logistics Group, and other combat units and support commands (Figure 17).

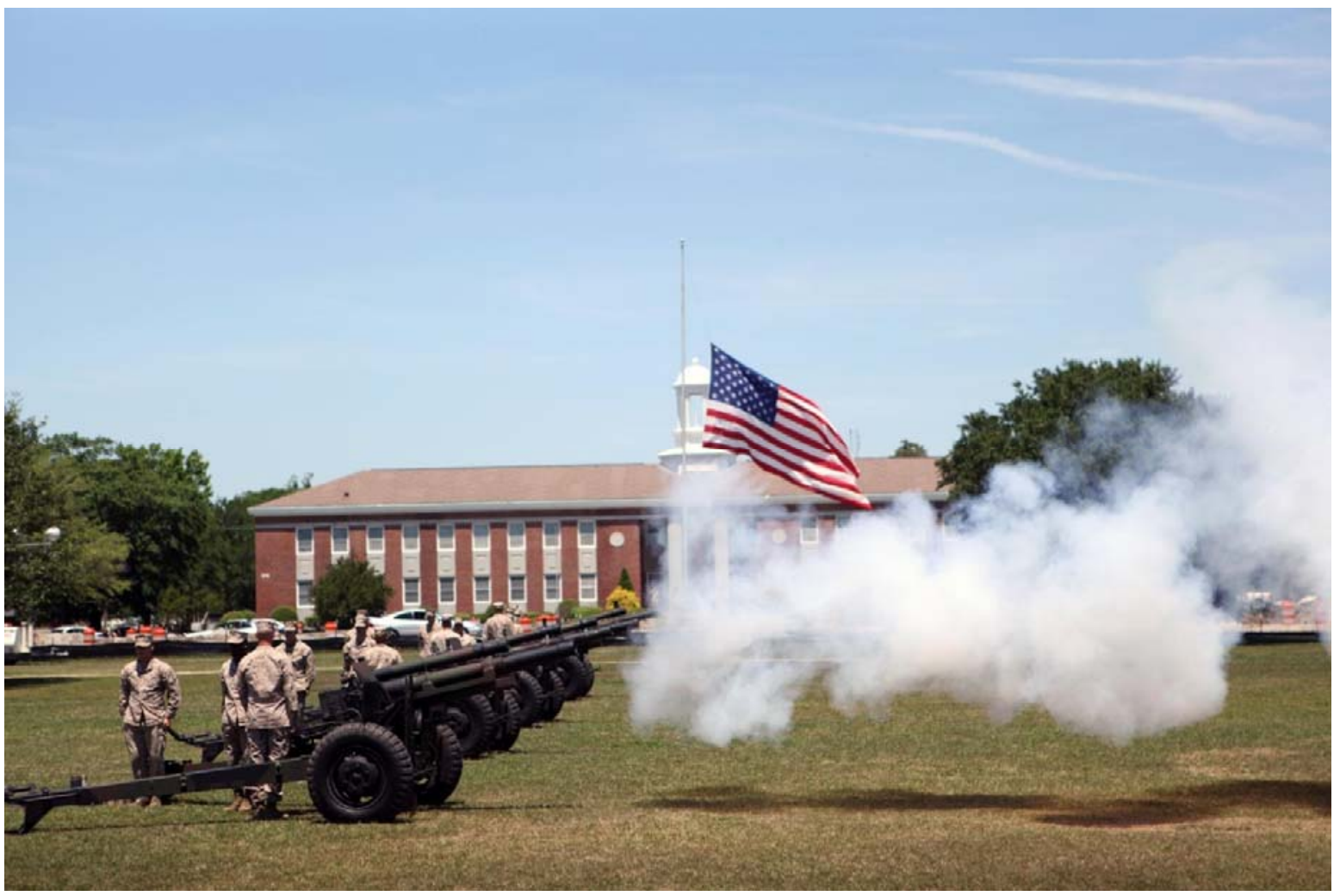

Figure 17. Memorial Day gun salute at MCBCL parade deck. ${ }^{3}$

\footnotetext{
${ }^{3}$ http://www.lejeune.marines.mil/Photos.aspx?igphoto=2000029387 photo by Cpl. Charlie Clark, accessed January 27, 2015.
} 
There are several major Marine Corps commands and one Navy command aboard Camp Lejeune. Some tenant commands (i.e., commands) include II MEF, $2^{\text {nd }}$ Marine Division, 2nd Marine Logistics Group, and the naval hospital to name a few. Marine Corps Base and Marine Corps Air Station (Marine Corps Installations East [MCIE]) own all real estate, host entry level and career-level formal schools, and provide support and training for commands. II MEF conducts operational planning for fleet Marine force commands; 2nd Marine Division is the ground combat element of II MEF; 2nd Marine Logistics Group is the combat service support element of II MEF; and 2nd Marine Air Wing (headquartered at Cherry Point, N.C.) is the air combat element of II MEF. ${ }^{4}$

The Motor Transport Division manages the non-tactical fleet of vehicles on MCBCL. For purposes of this study, vehicles are identified as assigned to MCIE departments and divisions or to commands. The commands operate 266 vehicles and MCIE operates the remaining 596 vehicles, which includes all pool vehicles. Of the vehicles in the study group, the commands operate 249 vehicles and MCIE operate 535. Table 2 shows the assignments of the vehicles in this study.

Table 2. MCBCL study vehicle assignments.

\begin{tabular}{lcccccccccc}
\hline & $\begin{array}{c}\text { Sedan } \\
\text { Compact }\end{array}$ & $\begin{array}{c}\text { Sedan } \\
\text { Midsize }\end{array}$ & $\begin{array}{c}\text { Sedan } \\
\text { Large }\end{array}$ & $\begin{array}{c}\text { Mini } \\
\text { van }\end{array}$ & SUV & Cargo & Pass & Pickup & Specialty & Total \\
\hline MCIE & 5 & 16 & 38 & 37 & 56 & 50 & 43 & 228 & 62 & 535 \\
Commands & 1 & 7 & 5 & 30 & 20 & 12 & 66 & 108 & 0 & 249 \\
Total & 6 & 23 & 43 & 67 & 76 & 62 & 109 & 336 & 62 & 784 \\
\hline
\end{tabular}

\section{VEHICLE MISSIONS}

\subsection{Mission Categories}

The vehicle mission is an important characteristic in the fleet study. Information used to define the vehicle mission includes the vehicle's configuration, vehicle use, classification per 40 CFR Part 600.31582 and EPA, the participating agency use, and general vehicle use. Based on fleet information gathered, Intertek has established the following seven mission/vehicle categories for analysis (examples are depicted in Figure 18):

1. Pool vehicles: A pool vehicle is any automobile (other than the low-speed vehicles identified below) manufactured primarily for use in passenger transportation, with not more than 10 passengers.

2. Enforcement vehicles: Vehicles specifically approved in an agency's appropriation act for use in apprehension, surveillance, police, or other law enforcement work. This category also includes site security vehicles, parking enforcement, and general use, but the vehicles are capable of requirements to support enforcement activities.

3. Support vehicles: Vehicles assigned to a specific work function or group to support the mission of that group. Vehicles are generally passenger vehicles or light-duty pickup trucks and may contain after-market modifications to support the mission.

4. Transport vehicles: Light, medium, or heavy-duty trucks used to transport an operator and tools or equipment of a non-specific design or nature. The vehicle's uses include repair, maintenance, or delivery.

5. Specialty vehicles: Vehicles designed to accommodate a specific purpose or mission (such as ambulances, mobile cranes, and handicap controls).

6. Shuttles/buses: Vehicles designed to carry more than 12 passengers and further outlined in 49 CFR 532.2.

\footnotetext{
${ }^{4}$ www.lejeune.marines.mil/About.aspx accessed January 22, 2015.
} 
7. Low-speed vehicles: Vehicles that are legally limited to roads with posted speed limits up to $45 \mathrm{mph}$ and that have a limited load-carrying capability.

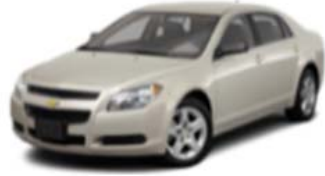

Pool Vehicle

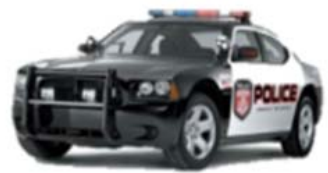

Enforcement Vehicle

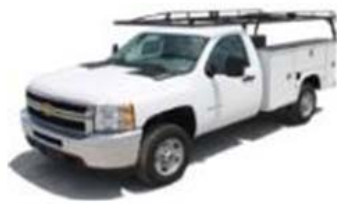

Support Vehicle

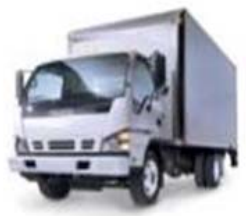

Transport Vehicle

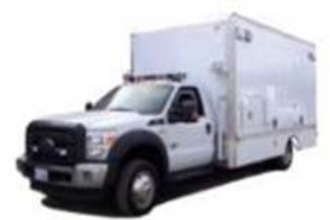

Specialty Vehicle

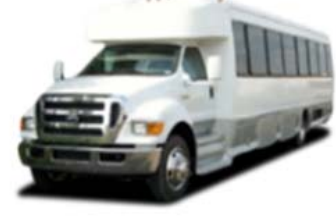

Shuttle / Bus

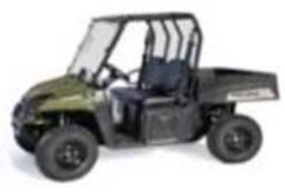

Low Speed

Vehicles

Figure 18. Vehicle missions.

\subsection{Vehicle Mission of Marine Corps Base Camp Lejeune Inventory}

The mission classification for the full inventory of vehicles is shown in Table 3 . This mission classification is not exact because some heavy-duty trucks may be in either the transport or the specialty categories. However, the approximate mission can be of value in determining the desirability of PEV replacements.

Table 3. Mission classification for full fleet.

\begin{tabular}{lcccccc}
\hline & Pool & Support & Enforcement & Transport & Specialty & Total \\
\hline MCIE & 111 & 339 & 79 & 7 & 60 & 596 \\
Commands & - & 259 & - & 7 & - & 266 \\
Total & 111 & 598 & 79 & 14 & 60 & 862 \\
\hline
\end{tabular}

Note that two specialty vehicles (i.e., regional brigs) are identified with the enforcement mission. For the vehicles in the study, the mission classifications are shown in Table 4.

Table 4. Mission classifications for study vehicles.

\begin{tabular}{lcccccc}
\hline & Pool & Support & Enforcement & Transport & Specialty & Total \\
\hline MCIE & 102 & 294 & 79 & - & 60 & 535 \\
Commands & & 249 & & & & 249 \\
Total & 102 & 543 & 79 & - & 60 & 784 \\
\hline
\end{tabular}

For the sedans in this study, the mission classifications are shown in Table 5.

Table 5. Mission classifications for sedans.

\begin{tabular}{lcccccc}
\hline & Pool & Support & Enforcement & Transport & Specialty & Total \\
\hline MCIE & 3 & 18 & 38 & - & - & 59 \\
Commands & - & 13 & - & - & - & 13 \\
Total & 3 & 31 & 38 & - & - & 72 \\
\hline
\end{tabular}




\section{OBSERVATIONS}

The MCBCL non-tactical fleet contains 784 vehicles for which PEV types are currently available or expected to be available in the next few years. A 60 -group subset of this fleet can be selected for further study for determination of mission and usage characteristics, which will be the focus of Task 2 . 